\title{
WEATHERING OF CARBONATE ROCKS \\ IN A POLLUTED URBAN ATMOSPHERE: THE MECHANISM OF PROCESSES
}

DOI: http://dx.doi.org/10.18509/GBP.2017.03

UDC: 552.54.04:504.5

\author{
Marek Michalik ${ }^{1}$ \\ Wanda Wilczyńska-Michalik ${ }^{2}$ \\ ${ }^{1}$ Institute of Geological Sciences, Jagiellonian University, Poland \\ ${ }^{2}$ Institute of Geography, Pedagogical University of Cracow, Poland
}

\begin{abstract}
For a long time, salt weathering was a dominant process of rock decay in polluted atmosphere in Kraków. Weathering zones developed on the Middle Triassic dolomite surfaces exposed to direct rain-washing and sheltered from rain were studied in order to discuss the influence of exposure conditions on the mechanism of weathering. Optical microscopy, scanning electron microscope with energy dispersive spectrometer, and Xray diffraction were used. On the walls exposed to rain, fragments exposed to intensive washing by rainwater are bright and devoid of secondary minerals. Less intensively washed surfaces are covered by a black brittle gypsum-rich crust. On the surface of the sheltered walls a dark grey crust has developed. It is composed of loosely packed agglomerations of platy gypsum crystals with abundant dust particles. Crystallisation of gypsum from rainwater and reactions of sulphur-containing components from the rainwater with $\mathrm{Ca}$ ion from the rock are important in the formation of black gypsum crust. The deposition of dust particles and adsorption of sulphur-containing components are the most important factors in the grey crust formation.
\end{abstract}

Keywords: rock weathering, polluted urban atmosphere, carbonate rocks

\section{INTRODUCTION}

High concentration of particulate and gaseous atmospheric pollutants in Kraków (South Poland) has caused accelerated weathering of building stones and the deterioration of numerous historical monuments. For a long period of time, salt weathering was a dominant process of rock decay. Crystallisation of salts in pore spaces was the reason for the high rate of rock weakening, followed by disintegration. Visual effects of the carbonate rocks' salt weathering were mostly related to their porosity [1]. Recent concentration of $\mathrm{SO}_{2}$ is significantly lower than in the last decades of the $20^{\text {th }}$ century, but particulate matter concentration is permanently high.

We compare weathering zones developed on the Middle Triassic dolomite surfaces exposed to direct rain-washing and sheltered from rain in order to discuss the influence of exposure conditions on weathering mechanisms. Exposure conditions are often considered as an important factor determining the importance of various weathering processes [2]. 


\section{MATERIAL AND ANALYTICAL METHODS}

The Middle Triassic dolomite (so-called Libiąż dolomite) was selected for the study because this rock was commonly used as a building material in Kraków at the end of the $19^{\text {th }}$ and beginning of the $20^{\text {th }}$ centuries; therefore, it is possible to find occurrences suitable for comparison. Samples from walls completely sheltered from rain (dry deposition environment) and walls exposed to rain-washing (wet and dry deposition environment) were studied. Samples from the dry deposition environment were collected under a bridge, while samples from the wet and dry deposition environment were collected from a wall situated near a street. Surface irregularity of the building blocks is the reason for the development of zones exposed to intense rain-washing and those partly sheltered and accessible to rainwater flowing down after precipitation.

Typical mineralogical and chemical methods were used (optical microscopy, scanning electron microscope with energy dispersive spectrometer, X-ray diffraction).

\section{RESULTS}

On the walls exposed to rain, two strongly contrasted zones are present. Fragments exposed to intensive washing by rainwater are bright, devoid of secondary minerals and subject to dissolution. In numerous blocks, in effect of dissolution fossils are visibly exposed. Less intensively washed surfaces are covered by a black brittle gypsum-rich crust composed of platy gypsum crystals (Fig. 1). Other sulphates occur rarely. It is possible to notice newly formed non-stoichiometric 'protodolomite' on the surface of the black crust. Different dust particles are dispersed between the gypsum crystals (both natural and anthropogenic) (Fig. 2). The black colour is related to the dark dust particles and organic pigment dispersed between the gypsum crystals.

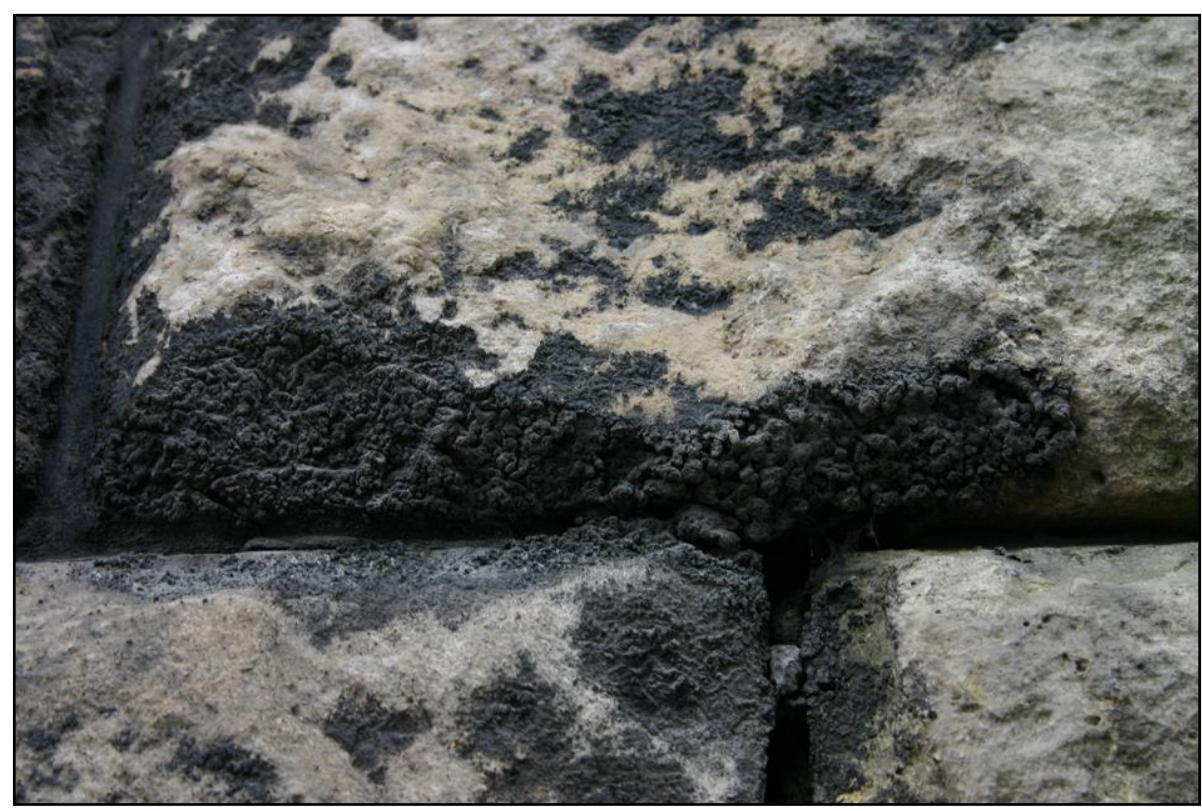

Figure 1. Black gypsum-rich crust. 


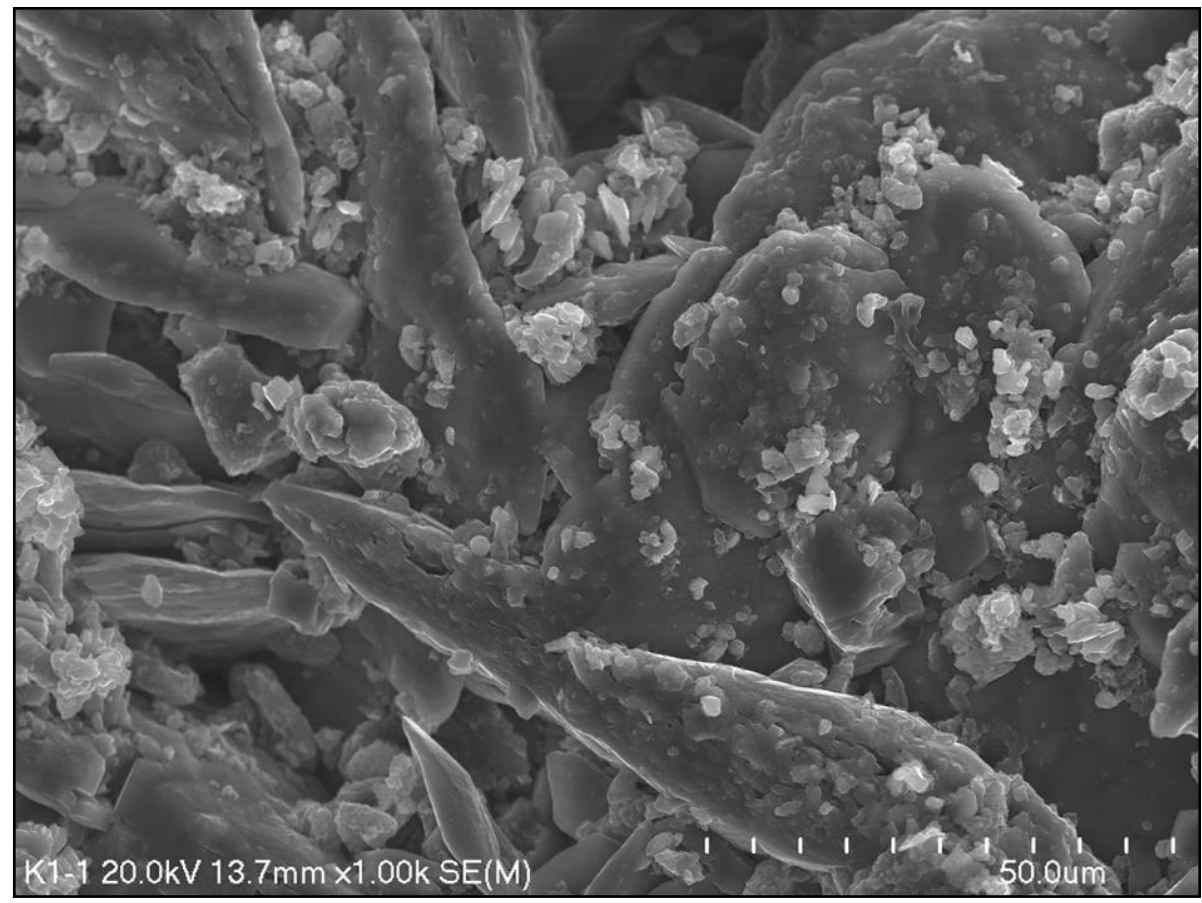

Figure 2. Platy gypsum crystals and dust particles.

On the surface of the sheltered walls a dark grey crust has developed (Fig. 3). It is composed of loosely packed agglomerations of platy gypsum crystals with abundant dust particles derived from soil or from resuspension from the street (quartz, mica, feldspars) and of anthropogenic origin (aluminosilicate spherules, iron-rich spherules or irregular grains, soot particles) (Fig. 4). Small amounts of authigenic calcite, halite and whewellite occur in this crust. The presence of easily soluble minerals is a typical difference between these two environments.

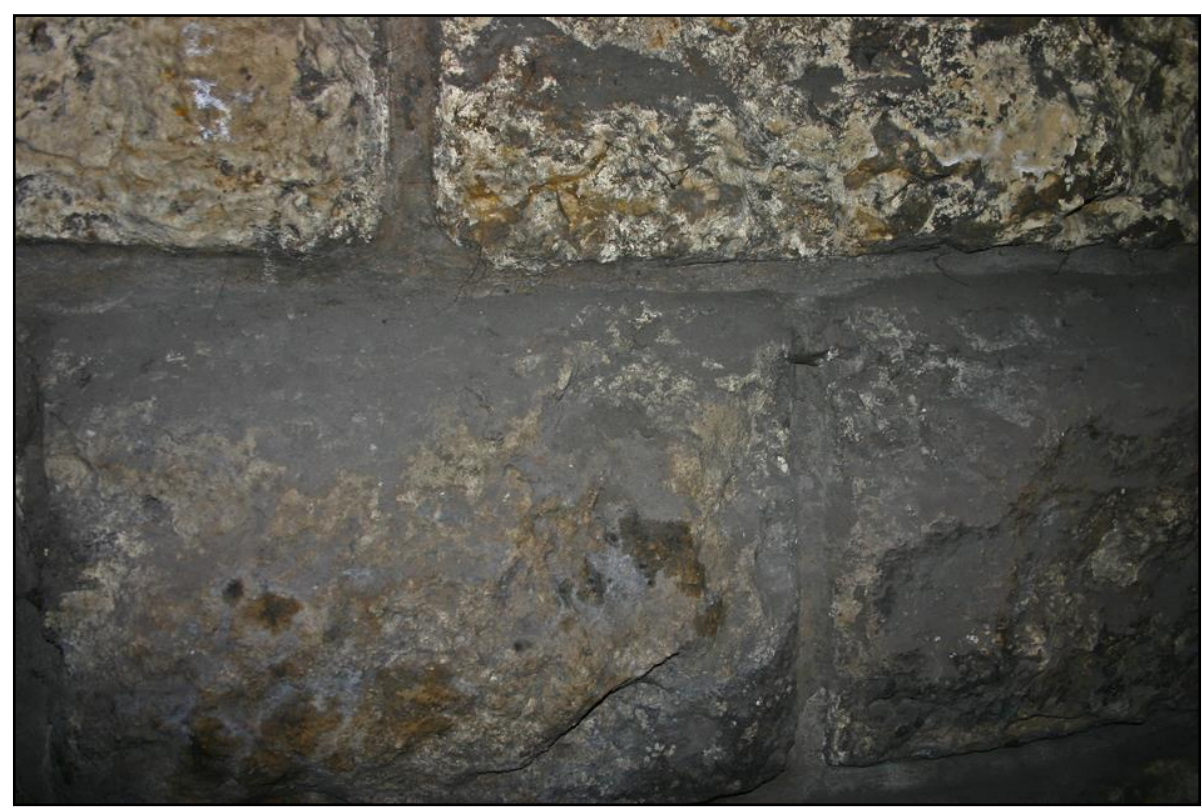

Figure 3. Dark grey crust on the surface of sheltered walls. 


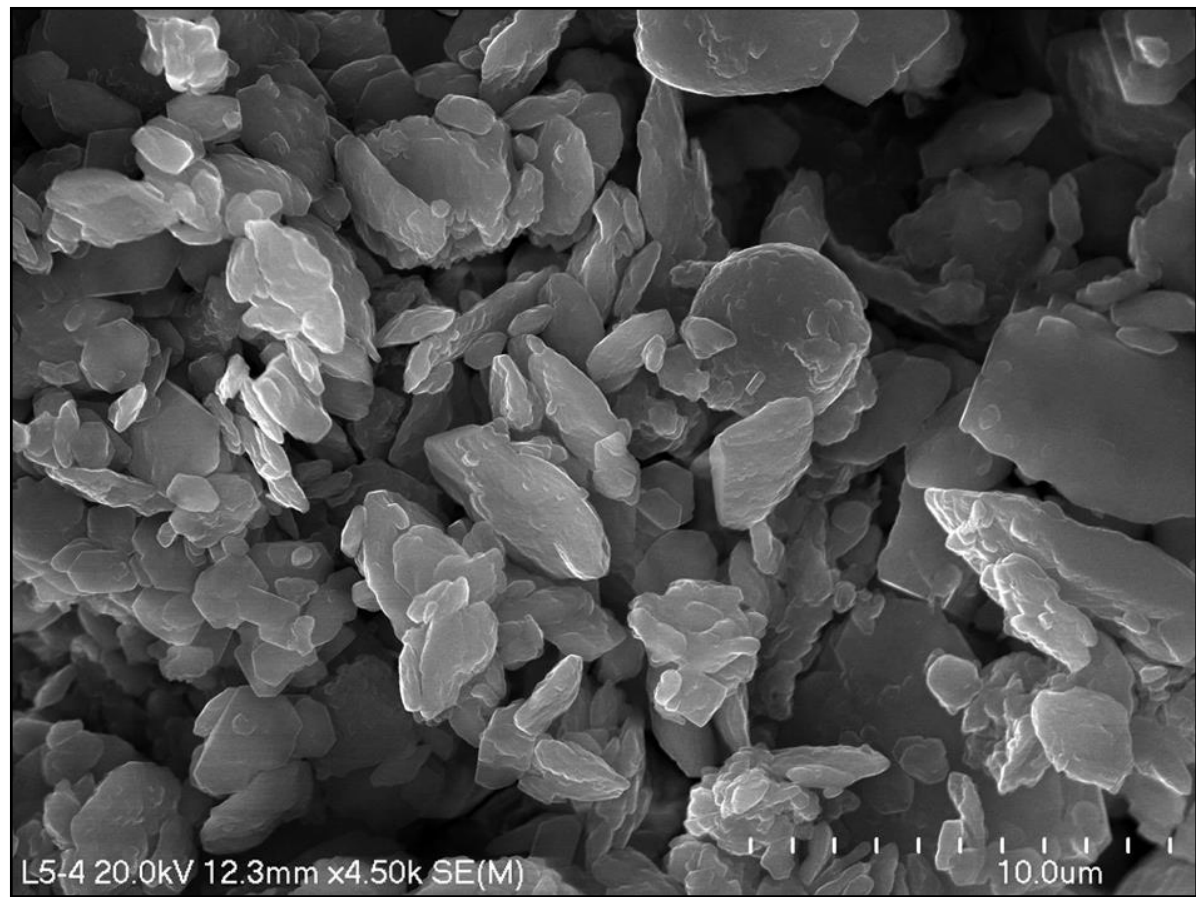

Figure 4. Loosely packed agglomerations of platy gypsum crystals with abundant dust particles.

The concentration of various elements is different in the black crust from rain-washed walls in comparison with the grey crust on sheltered walls. Higher concentrations of numerous elements in the grey crust from sheltered walls are related to the elevated amount of dust. Dust particles are systematically removed from rain-washed surfaces, causing the lower concentration of some elements. The isotopic ratios of sulphur and oxygen in gypsum from both groups of samples are very similar.

\section{DISCUSSION AND CONCLUSIONS}

Crystallisation of gypsum from rainwater is important in the formation of black gypsum crust on rocks exposed to rain-washing [1], [3]. Gypsum formation can also be related to reactions of sulphur-containing components from the rainwater with $\mathrm{Ca}$ ion from the rock. The presence of 'protodolomite' is additional evidence of the dissolution of dolomite as a source of $\mathrm{Mg}$. The downward movement of solution containing newly crystallised gypsum crystals is the reason for the folded surface of the crust. Dust particles deposited on the rock surface are removed during subsequent rain-washing. Adsorption of sulphurcontaining components on the dry or moist surfaces of walls during periods between precipitation is probably negligible in the black crust formation.

The deposition of dust particles and adsorption of sulphur-containing components are the most important factors in the grey crust formation. The condensation of water vapour on sheltered walls causes significant moisture retention on the surface and facilitates both the deposition of dust and formation of sulphate anions and gypsum crystallisation. The rate of sulphate anions' formation is increased because of the catalytic role of metal contained in the dust particles in sulphur dioxide oxidation. Hyphae filaments and spider webs participate in the binding of loose crust components. 


\section{REFERENCES}

[1] Wilczyńska-Michalik W. Influence of atmospheric pollution on the weathering of stones in Cracow monuments and rock outcrops in Cracow, Cracow-Częstochowa Upland and the Carpathians, Wydawnictwo Naukowe Akademii Pedagogicznej, pp 1 247, 2004.

[2] Turkington A.V., Martin E., Viles H.A. \& Smith B.J. Surface change and decay of sandstone samples exposed to a polluted urban atmosphere over a six-year period: Belfast, Northern Ireland. Building and Environment, vol. 38, pp 1205-1216, 2003. [3] Wilczyńska-Michalik W. \& Michalik M. Mineral composition and structure of crusts on dolomitic building materials in urban atmosphere in Kraków. Mineralogia Polonica, vol. 22, pp. 69-78, 1991. 